\title{
Complete mutation scan of the human Fas ligand gene: Linkage studies in Type I diabetes mellitus families
}

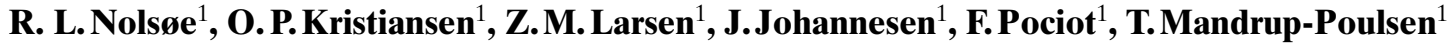 \\ ${ }^{1}$ Steno Diabetes Center, Gentofte, Denmark
}

\section{Abstract}

Aims/hypothesis. Type I (insulin-dependent) diabetes mellitus is the result of a T-cell regulated selective destruction of pancreatic beta cells. There is evidence that the apoptosis inducing T-cell effector, Fas ligand (FasL) could be involved in the pathogenesis of Type I diabetes, probably because FasL-mediated apoptosis is important in maintaining peripheral self-tolerance and in down-regulating an immune response. We therefore evaluated the human FasL gene FASL on chromosome 1q23 as a candidate susceptibility gene for Type I diabetes.

Methods. The entire FASL (promoter, exons 1-4 and 3'UTR) was scanned for polymorphisms using single strand conformational polymorphism-heteroduplex analysis and direct sequencing.
Results. We identified two novel polymorphisms, a $g$ $C 843 T$ and a $g-A 475 T$, in a negative regulatory region of the promoter. A Danish Type I diabetes family collection of 1143 subjects comprising 257 families ( 420 affected and 252 unaffected offspring) was typed for the g-C843T polymorphism and for a FASL microsatellite. Haplotypes were established and data were analysed using the extended transmission disequilibrium test.

Conclusion/interpretation. We found no overall evidence for linkage in the presence of association of the FASL polymorphism to Type I diabetes and conclude that FASL does not contribute to the genetic susceptibility to Type I diabetes. [Diabetologia (2002) 45: 134-139]

Keywords Genetics, candidate gene, microsatellite, apoptosis, immune regulation, T cells, tolerance, SP$1, \mathrm{NF}-\varkappa \mathrm{B}$.
Received: 4 July 2001 and in revised form: 12 September 2001

The authors represent The Danish Study Group of Diabetes in Childhood (DSGD) and The Danish IDDM Epidemiology and Genetics Group (DIEGG)

Corresponding author: Prof. T. Mandrup-Poulsen, Steno Diabetes Center, 2, Niels Steensensvej 2820 Gentofte, Denmark, e-mail: tmpo@novonordisk.com

Abbreviations: 3' UTR, 3' Untranslated region; AP-1, activation protein - 1; Egr-3, early growth response protein - 3; IFN, interferon; IRF-1, IFN regulatory factor -1 ; $\mathrm{kb}$, kilobases; lpr, lymphoproliferative; NFAT, nuclear factor of activated $\mathrm{T}$ cell; NF- $\varkappa \mathrm{B}$, nuclear factor $-\varkappa \mathrm{B}$; NK, natural killer; NOD, nonobese diabetic mouse; PAGE, polyacryl amide gel electrophoresis; PCR, polymerase chain reaction; SLE, systemic lupus erythematosus; SSCP, single strand conformation polymorphism; TCR, T cell receptor; TDT, transmission disequilibrium test; TNF, tumor necrosis factor; VNTR, variable number of tandem repeats
Type I (insulin-dependent) diabetes mellitus is the result of an immune mediated selective destruction of pancreatic beta cells, in which macrophages and Thelper cells play a crucial role. There is evidence in humans and in murine models of Type I diabetes that beta-cell death occurs by apoptosis $[1,2]$.

The apoptosis inducing T-cell effector, Fas ligand (FasL), is a $40000 \mathrm{M}_{\mathrm{r}}$ type II membrane protein belonging to the tumor necrosis factor (TNF) family. FasL induces apoptosis when binding to its receptor, Fas. FasL is predominantly expressed in activated $\mathrm{T}$ lymphocytes, in natural killer cells and in immune privileged sites, such as the testes and eye [3]. The human FasL gene, FASL, has four exons spanning more than $9 \mathrm{~kb}$ and maps to $1 \mathrm{q} 23$ [4]. Polymorphisms of the murine $F A S L$ that affect the biological activity have been described [5] as well as an 84 bp deletion in 
exon 4 in one patient with systemic lupus erythematosus (SLE) and lymphoproliferative disease [6].

In murine models of Type I diabetes FasL does not seem to be an effector molecule in beta-cell apoptosis but rather plays a role in the deletion of autoreactive $\mathrm{T}$ cells both in the thymus and in the periphery. Hence, Fas deficient NOD lpr/lpr mice do not develop spontaneous diabetes and accumulate large amounts of FasL expressing abnormal double negative (Thy $1+\mathrm{B} 220+\mathrm{CD}^{-} \mathrm{CD}^{-}$) $\mathrm{T}$ cells [7] in the lymphoid system. FasL mediated apoptosis is involved in clonal thymic deletion of thymocytes that are reactive to antigens highly expressed in the thymus [8]. The lpr mutation is leaky and a small amount of normal Fas is expressed in the thymus of $l p r$ mice [9] and it is possible that NOD lpr/lpr mice do not develop diabetes because they have an intact FasL mediated deletion of autoreactive thymocytes. In humans, the dominant protective INS class III VNTR allele is associated with higher steady-state levels of thymic INS mRNA expression and could promote deletion of insulin-specific T-lymphocytes [10].

NOD $l p r / l p r$ mice are also protected from adoptive transfer of diabetes, probably because host FasL-expressing double negative T cells kill the Fasexpressing transferred diabetogenic T cells. Soluble FasL induces apoptosis of potentially autoreactive CD4 + CD45RB ${ }^{\text {low }}$ memory T cells [11].

$F A S / F A S L$ are therefore attractive candidate susceptibility genes for Type I diabetes. We have recently scanned the entire human $F A S$ for mutations and tested the frequent polymorphisms for linkage in a large Danish Type I diabetes multiplex family but we found no evidence for linkage [12]. Therefore we have scanned the human FASL for mutations and report our results.

\section{Subjects and methods}

Subjects. SSCP-heteroduplex analysis and direct sequencing were carried out in 20 unrelated Type I diabetes patients and 20 healthy control subjects of Danish Caucasian ancestry.

Linkage analysis was carried out in a Danish Type I diabetes family cohort (a total of 1143 individuals) comprising 154 sib pair families (a total of 725 individuals, 317 affected and 138 unaffected offspring) and 103 simplex families (a total of 418 individuals, 103 affected and 114 unaffected offspring). All index cases, defined as the first affected offspring, had onset of Type I diabetes mellitus before the age of 30 years (mean \pm SD: $10.0 \pm 5.5$ years). All affected offspring had onset of Type I diabetes before age 30 years (mean \pm SD: $10.0 \pm 4.8$ years). All families were unrelated. Approval for the study was obtained from the Ethics Committee of Copenhagen County.

Screening for and identification of mutations in the human FASL. Primers for PCR were designed from the genomic human FASL sequence (GenBank AC Z96050) to generate 17 overlapping PCR products 202-279 bp long (Table 1) with an average overlap of $51 \mathrm{bp}$. The PCR mixture comprised
$0.8 \mu \mathrm{mol} / \mathrm{l}$ of each primer, $50 \mu \mathrm{mol} / \mathrm{l} \mathrm{dNTPs}, 1.0-1.5 \mathrm{mmol} / \mathrm{l}$ $\mathrm{MgCl}_{2}, 0.5 \mathrm{U} /$ sample Taq DNA Polymerase (Promega Corporation, Madison, Wis., USA) with $1 \mathrm{x}$ reaction buffer and 40 ng genomic DNA in a total reaction volume of $25 \mu \mathrm{l}$. The cycling conditions were $95^{\circ} \mathrm{C}$ for $5 \mathrm{~min}$., followed by 30 to $35 \mathrm{cy}-$ cles of $95^{\circ} \mathrm{C}$ for $30 \mathrm{~s}, 48$ to $60^{\circ} \mathrm{C}$ for $30 \mathrm{~s}$ and $72^{\circ} \mathrm{C}$ for $30 \mathrm{~s}$, and $72^{\circ} \mathrm{C}$ for $10 \mathrm{~min}$.

SSCP-heteroduplex analysis utilised the 17 PCR amplicons listed in Table 1, using the Gene Gel Excel 12.5, 24 kit and GeneGel Clean 15, 24 kit with the PhastSystem (Amersham Pharmacia Biotech, Uppsala, Sweden) as described in [12]. Samples were run on the GenePhor electrophoresis unit (Amersham Pharmacia Biotech, Uppsala, Sweden) and gels were stained using the Plus One DNA Silver Staining Kit (Amersham Pharmacia Biotech, Uppsala, Sweden) on a Hoefer Automated Gel Stainer (Pharmacia Biotech, San Francisco, Calif., USA). Samples demonstrating mobility shifts or heteroduplex formation were sequenced by cycle sequencing using the PCR product pre-sequencing kit and the thermo sequennase cycle sequencing kit (both Amersham Pharmacia Biotech, Cleveland, Ohio, USA) as described in [12].

Direct sequencing of the FASL promoter from position -475 to -104 (relative to the start codon) was done on an ABI Prism 310 DNA sequencer system (Perkin Elmer, Foster City, Calif., USA).

Typing for the g-C843T polymorphism. We typed for the $g$ C843T polymorphism by mutagenically separated PCR (MSPCR) as described in [13] using the forward primers (mutant): 5'AATGAAAATGAAAACATTGT, (wildtype): 5'TAAATAAGTAAATAAATAAACTGGGCAAACCTTGAAAATGAAAACAACGC and reverse primer: 5'CCCACTTTAGAAATTAGATC to yield a PCR product of $114 \mathrm{bp}$ for the wildtype and $84 \mathrm{bp}$ for the mutant allele. Assay conditions were: forward primers (wildtype) $1.0 \mu \mathrm{mol} / 1$, (mutant) and reverse primer $0.5 \mu \mathrm{mol} / 1$ each, dNTPs $50 \mu \mathrm{mol} / \mathrm{l}, \mathrm{MgCl}_{2}$ $1.0 \mathrm{mmol} / \mathrm{l}$, Taq DNA Polymerase (Promega Corporation) 0.5 U/sample with $1 \mathrm{X}$ Reaction buffer and $40 \mathrm{ng}$ genomic DNA in a reaction volume of $20 \mu \mathrm{l}$. Cycling conditions were $95^{\circ} \mathrm{C}$ for $3 \mathrm{~min}, 45$ cycles of $95^{\circ} \mathrm{C}$ for $30 \mathrm{~s}, 45^{\circ} \mathrm{C}$ for $30 \mathrm{~s}$ and $72^{\circ} \mathrm{C}$ for $30 \mathrm{~s}$, and $72^{\circ} \mathrm{C}$ for $10 \mathrm{~min}$. PCR products were separated by gel electrophoresis on a $4 \%$ agarose gel.

FASL microsatellite. Primer sequences are shown (Table 1) [14]. Using biotinylated primers we typed the FASL microsatellite by PCR of $40 \mathrm{ng}$ genomic DNA template followed by PAGE, blotting and visualisation utilising a streptavidin-peroxidase (Sigma, St. Louis, Mo., USA) catalysed ECL reaction (Amersham Life Science, Cleveland, Ohio., USA) [12]. PCR cycling conditions were $95^{\circ} \mathrm{C}$ for $5 \mathrm{~min}, 35$ cycles of $95^{\circ} \mathrm{C}$ for $30 \mathrm{~s}, 55^{\circ} \mathrm{C}$ for $30 \mathrm{~s}$ and $72^{\circ} \mathrm{C}$ for $30 \mathrm{~s}$, and $72^{\circ} \mathrm{C}$ for $10 \mathrm{~min}$. Samples homozygous for the different alleles were confirmed by sequencing on an ABI Prism 310 DNA sequencer system (Perkin Elmer, Foster City, Calif., USA).

Statistical analysis. Transmission disequilibrium test (TDT) for linkage and extended transmission disequilibrium test (ETDT) for linkage with multiallele markers were carried out [16]. The TDT is a test of association between alleles at a marker and a disease and requires linkage disequilibrium (allelic association maintained by tight linkage) between the marker alleles and the unknown gene polymorphism. The TDT detects deviations from random transmission of alleles to disease phenotypes as expected based on Hardy-Weinberg equilibrium. The TDT is still a valid test of linkage, when more than one affected offspring per family are considered. Statistical significance of $5 \%$ was chosen. Linkage disequilibri- 
Table 1. Primers for human FASL

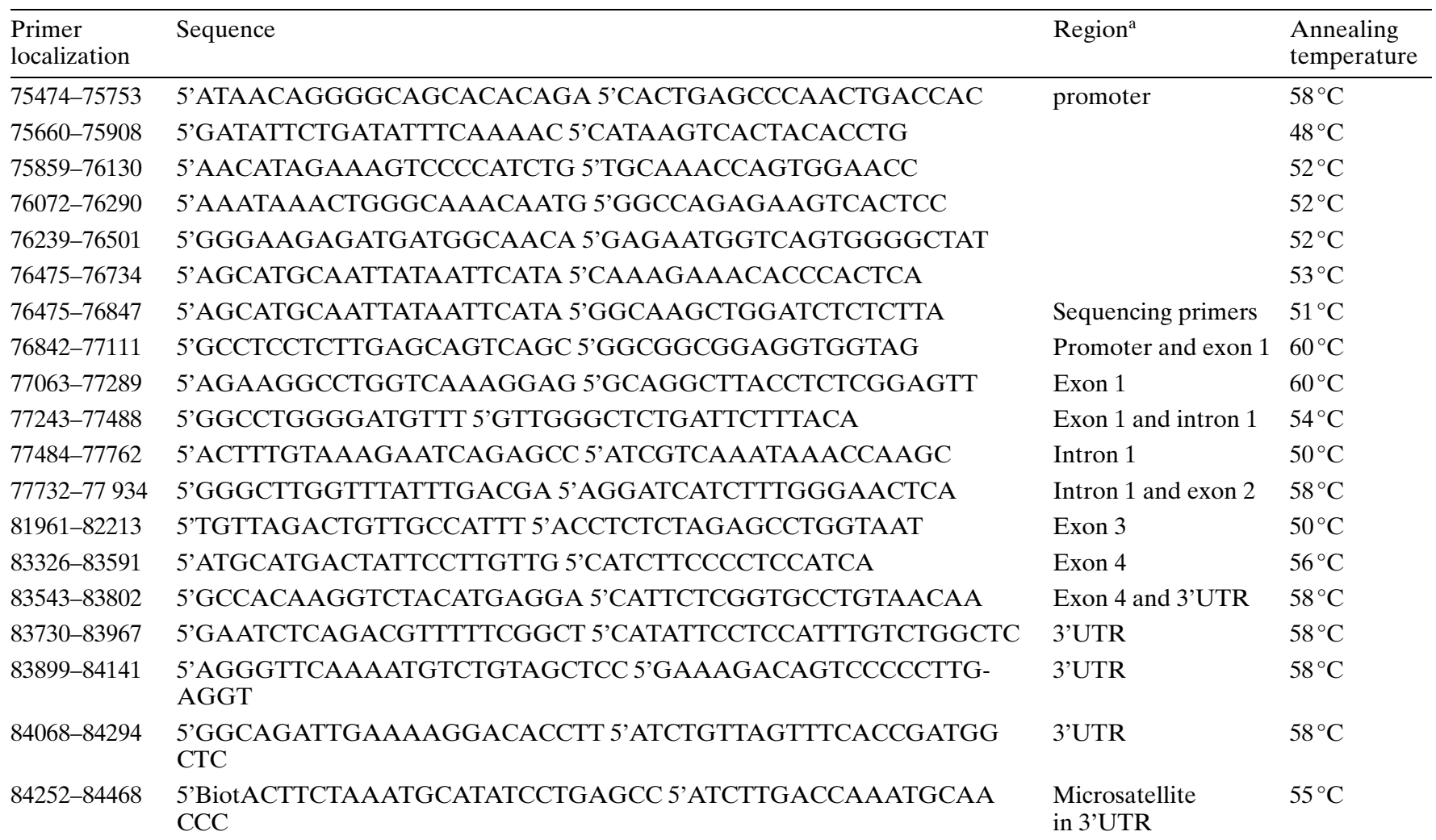

GenBank AC Z96050

${ }^{a}$ Including flanking exon-intron boundaries

um was calculated as the disequilibrium coefficient $D[17][D=$ $P_{11}-p_{1} q_{1}$,] where $p_{1}$ is the frequency of the "most frequent" allele at locus 1 in the general population, $q_{1}$ is the population frequency of the "most frequent" allele at locus 2 and $P_{11}$ is the observed frequency of the haplotype formed by these alleles.

The heterozygosity index is defined as the percentage of parents who are heterozygous for the polymorphism that is being tested.

\section{Results}

Mutation detection by SSCP-heteroduplex analysis and direct sequencing. The entire human FASL (promoter, exons 1-4 including exon-intron boundaries and the 3'UTR) was screened for mutations by SSCP- heteroduplex analysis followed by direct sequencing of polymorphic variants in 40 unrelated Danish Caucasians (20 Type I diabetic patients and 20 healthy control subjects), using the 17 PCR amplicons established from the genomic FASL sequence and listed in Table 1 . The FASL promoter was directly sequenced from position -475 to -104 (relative to the start codon) in the same 40 subjects. In the entire human FASL we identified a total of two novel polymorphisms, a $g$-C843T and a $g-A 475 T$, both situated in the promoter.

\section{Linkage analysis}

FASL promoter polymorphisms. The TDT [15] was applied to analyse the $g$-C843T polymorphism for linkage in the presence of association to Type I diabetes. The parental heterozygosity index was 0.51 . We found no evidence for linkage, $\mathrm{P}_{\mathrm{TDT}} \geq 0.13$ (Table 2).

A high throughput typing method for the $g$-A475T polymorphism could not be established. To type for this polymorphism, which does not lead to an altered restriction enzyme site, we have tried to establish an MS-PCR assay and a single nucleotide primer extension analysis. We could not type for the polymorphism by SSCP, as the SSCP pattern was not unequivocal. The frequencies of the $\mathrm{A}$ and $\mathrm{T}$ allele were 0.82 and 0.18 , respectively in our screening panel of 20 Type I diabetic patients and 20 control subjects. The $\mathrm{T}$ allele was in linkage disequilibrium with the $\mathrm{T}$ allele of the $g$-C843T polymorphism.

FASL microsatellite. The Danish family collection was typed for a FASL microsatellite (GT repeat polymorphism) [14] localized in the 3'UTR within $600 \mathrm{bp}$ of exon 4. Seven alleles ranging from 14 to 22 GT repeats were observed. The 16 and 17 repeat alleles were the most frequent with allelic frequencies of 0.795 and 0.18 , respectively. The parental heterozy- 
Table 2. FASL promoter g-C843T polymorphism: allelic transmission patterns from heterozygous parents to offspring

\begin{tabular}{llll}
\hline & $\mathrm{C}$ & $\mathrm{T}$ & $\chi^{2}$ \\
\hline Affected & 160 & 134 & 2.3 \\
Index cases & 103 & 87 & 1.4 \\
Unaffected & 99 & 89 & 0.5
\end{tabular}

Allele frequencies in the parental generation were 0.6 and 0.4 for the $\mathrm{C}$ and $\mathrm{T}$ allele, respectively and parental heterozygosity index was 0.51 . (TDT) $p \geq 0.13, \geq 0.25, \geq 0.47$, for affected, index cases and unaffected, respectively

gosity index was 0.32. Data were analysed for linkage in the presence of association using the ETDT [16] (Table 3; $\mathrm{P}_{\mathrm{ETDT}} \geq 0.015$ ). The results showed preferential transmission of the 16 allele from heterozygous parents to all offspring (58\% and $54 \%$ to affected and unaffected offspring, respectively) and showed no significant difference in transmission patterns between affected and unaffected offspring when compared by the $\chi^{2}$ test $(p \geq 0.5)$.

FASL haplotypes. Haplotypes were established from the $g$-C843T polymorphism and the 16 and 17 alleles of the FASL microsatellite and tested for linkage to Type I diabetes using the ETDT (Table 4). The parental heterozygosity index was 0.63 , and we found no evidence for linkage, $\mathrm{P}_{\mathrm{ETDT}} \geq 0.2$.

\section{Linkage disequilibrium}

The disequilibrium coefficient $D$ [17] for the $g$-C843T polymorphism and the FASL microsatellite was calculated to be 0.05 .

\section{Discussion}

We have screened the entire human FASL for mutations by SSCP-heteroduplex analysis followed by direct sequencing of polymorphic variants.

In addition we have sequenced the promoter from -475 to -104 , an area containing the NFAT binding site essential for FASL transcription in T-cell activa- tion via the TCR, CD3 and CD4 [18] as well as binding sites for nuclear factor- $x \beta$ (NF- $x \beta)$, early growth response protein -3 (Egr-3), IFN regulatory factor -1 (IRF-1) and activating protein-1 (AP-1)[3].

We identified two novel polymorphisms in the promoter, a $g$ - $C 843 T$ and a $g$ - $A 475 T$. These are located in a negative regulatory region of the promoter [18] but do not alter transcription factor bindings sites.

A mutagenically separated PCR (MS-PCR) assay [13] was established to type a large Danish Type I diabetic multiplex family collection for the informative $g$-C843T polymorphism and data were analysed for linkage in the presence of association to Type I diabetes by the transmission disequilibrium test [15]. However, we did not find evidence for linkage.

We also typed the Danish family collection for a FASL microsatellite [14] localized in the 3'UTR of $F A S L$, and analysed data for linkage to Type I diabetes using the extended transmission disequilibrium test [16]. However, these results do not indicate linkage in the presence of association as one could be led to believe if testing transmissions only to affected offspring. When considering transmissions from heterozygous parents to all offspring, the results showed preferential transmission of the most frequent allele, 16 repeat allele, to affected and as well as unaffected offspring and no significant difference in transmission patterns of the 16 repeat allele. The skewed transmission of the 16 allele could be due to meiotic segregation distortion and not to linkage to Type I diabetes. This emphasizes the importance in testing the transmissions to unaffected as well as affected offspring [15].

We then established haplotypes from the $g$-C843T polymorphism and the 16 and 17 alleles of the FASL microsatellite and tested these for linkage using the ETDT. The haplotypes were highly informative, since $63 \%$ of the parents were heterozygous. We found no evidence for linkage of the FASL haplotypes to Type I diabetes.

The disequilibrium coefficient $D$ [17] for the $g$ C843T polymorphism and the FASL microsatellite was calculated to be 0.05 , which indicates only weak linkage disequilibrium between these two polymorphisms situated less than $9 \mathrm{~kb}$ apart.

Table 3. FASL microsatellite; allelic transmission patterns of the two most frequent alleles from heterozygous parents to offspring

\begin{tabular}{|c|c|c|c|c|c|}
\hline & $\begin{array}{l}\text { Allele size } \\
\text { (repeat units) }\end{array}$ & Transmitted & Non transmitted & $\chi^{2}$ & $p$ value ${ }^{\mathrm{a}}$ \\
\hline Affected & $\begin{array}{l}16 \\
17\end{array}$ & $\begin{array}{r}117 \\
78\end{array}$ & $\begin{array}{r}85 \\
102\end{array}$ & $\begin{array}{l}5.07 \\
3.2\end{array}$ & $\begin{array}{l}0.02 \\
0.07\end{array}$ \\
\hline Index cases & $\begin{array}{l}16 \\
17\end{array}$ & $\begin{array}{l}71 \\
51\end{array}$ & $\begin{array}{l}54 \\
59\end{array}$ & $\begin{array}{l}2.31 \\
0.58\end{array}$ & $\begin{array}{l}0.13 \\
0.45\end{array}$ \\
\hline Unaffected & $\begin{array}{l}16 \\
17\end{array}$ & $\begin{array}{l}61 \\
42\end{array}$ & $\begin{array}{l}51 \\
58\end{array}$ & $\begin{array}{l}0.89 \\
2.56\end{array}$ & $\begin{array}{l}0.34 \\
0.11\end{array}$ \\
\hline
\end{tabular}

Parental heterozygosity index 0.32

${ }^{a}$ Uncorrected $p$ values. (ETDT) $p \geq 0.015, \geq 0.13, \geq 0.24$ for affected, index cases and unaffected, respectively 
Table 4. FASL haplotype (established from the $g$-C843T promoter polymorphism and the two most frequent alleles of the microsatellite in the 3 'UTR of $F A S L$ ) transmissions

\begin{tabular}{|c|c|c|c|c|c|}
\hline & Haplotype & Transmitted & Non transmitted & $\chi^{2}$ & $p$ value $^{\mathrm{a}}$ \\
\hline Affected & $\begin{array}{l}\text { T16 } \\
\text { T17 } \\
\text { C16 } \\
\text { C17 }\end{array}$ & $\begin{array}{r}112 \\
36 \\
150 \\
42\end{array}$ & $\begin{array}{r}124 \\
44 \\
118 \\
54\end{array}$ & $\begin{array}{l}0.6 \\
0.8 \\
3.8 \\
1.5\end{array}$ & $\begin{array}{l}0.43 \\
0.37 \\
0.05 \\
0.22\end{array}$ \\
\hline Index cases & $\begin{array}{l}\text { T16 } \\
\text { T17 } \\
\text { C16 } \\
\text { C17 }\end{array}$ & $\begin{array}{l}74 \\
22 \\
89 \\
30\end{array}$ & $\begin{array}{l}78 \\
27 \\
79 \\
31\end{array}$ & $\begin{array}{l}0.1 \\
0.5 \\
0.6 \\
0.02\end{array}$ & $\begin{array}{l}0.75 \\
0.48 \\
0.44 \\
0.90\end{array}$ \\
\hline
\end{tabular}

Transmission patterns of haplotypes from heterozygous parents to offspring. The frequencies of haplotypes in the parental generation were: T16: 0.34, T17: 0.07, C16: 0.50, C17: 0.09 and the parental heterozygosity index was 0.63

${ }^{\mathrm{a}}$ Uncorrected $p$ values. (ETDT) $p \geq 0.2$
Power estimates assuming a $12.5 \%$ deviation show that the probability of making a type II error at $5 \%$ in the statistical analysis is low due to the many observed transmissions.

The risk that we have overlooked polymorphisms in the human FASL that are linked to Type I diabetes is small, since the sensitivity and specificity of the SSCP-heteroduplex analysis in our laboratory is high [12] and in addition we have sequenced the 3' area of the promoter involved in FASL expression in $\mathrm{T}$ cells in 40 subjects. Minor susceptibility genes are expected to modify risk and are likely to be frequent in the general population. We have identified another polymorphism, $g$ - $A 475 T$, which was checked by sequencing in the screening panel only. This polymorphism is in linkage disequilibrium with the $g$-C843T polymorphism and we therefore find it unlikely that the $g-A 475 T$ polymorphism should independently be associated with Type I diabetes.

In summary, we have scanned the entire human $F A S L$ and identified two novel polymorphisms in a negative regulatory region of the FASL promoter. These are, however, not linked under the assumption of association with Type I diabetes but could be relevant for the understanding of the genetic susceptibility to other immune mediated disorders.

Acknowledgements. We highly appreciate the work of The Danish Study Group of Diabetes in Childhood (DSGD) as well as the Danish IDDM Epidemiology and Genetics Group (DIEGG) in family collection. For participating departments, see [19]. We are grateful for the skilful technical assistance of A. H. Schram, M. Deckert, J. Ahnfelt-Rønne and N. Hadrup. This study was supported by grants from The Danish Diabetes Association, The King Christian X Foundation, The Poul and Erna Sehested Hansen Foundation and by Novo Nordisk A/S. O.P. Kristiansen is a recipient of a Research Fellowship from JDFI (JDFI grant No. 3-1999-21). Z. M. Larsen was supported by the Danish Medical Research Council (No. 9802011).

\section{References}

1. Delaney C, Pavlovic D, Hoorens A, Pipeleers D, Eizirik D (1997) Cytokines induce deoxyribonucleic acid strand breaks and apoptosis in human pancreatic islet cells. Endocrinology 138: 2610-2614

2. O'Brien B, Harmon B, Cameron D, Allan D (1997) Apoptosis is the mode of beta-cell death responsible for the development of IDDM in the nonobese diabetic (NOD) mouse. Diabetes 46: 750-757

3. Nagata S (1999) Fas ligand-induced apoptosis. Annu Rev Genet 33: 29-55

4. Takahashi T, Tanaka M, Inazawa J, Abe T, Suda T, Nagata S (1994) Human Fas ligand: gene structure, chromosomal location and species specificity. Int Immunol 6: 1567-1574

5. Kayagaki N, Yamaguchi N, Nagao F et al. (1997) Polymorphism of murine Fas ligand that affects the biological activity. Proc Natl Acad Sci USA 94: 3914-3919

6. Wu J, Wilson J, He J, Xiang L, Schur P, Mountz J (1996) Fas ligand mutation in a patient with systemic lupus erythematosus and lymphoproliferative disease. J Clin Invest 98: 1107-1113

7. Chervonsky A, Wang Y, Wong F et al. (1997) The role of Fas in autoimmune diabetes. Cell 89: 17-24

8. Kishimoto H, Surh C, Sprent J (1998) A role for Fas in negative selection of thymocytes in vivo. J Exp Med 187: 1427-1438

9. Adachi M, Suematsu S, Suda T et al. (1996) Enhanced and accelerated lymphoproliferation in Fas-null mice. Proc Natl Acad Sci USA 93: 2131-2136

10. Pugliese A, Zeller M, Fernandez A et al. (1997) The insulin gene is transcribed in the human thymus and transcription levels correlated with allelic variation at the INS VNTRIDDM 2 susceptibility locus for type 1 diabetes. Nat Genet 15: 293-297

11. Kim S, Kim K, Hwang D et al. (2000) Inhibition of autoimmune diabetes by Fas ligand: The paradox is solved. J Immunol 164: 2931-2936

12. Nolsoe R, Kristiansen O, Sangthongpitag K et al. (2000) Complete molecular scanning of the human Fas gene: mutational analysis and linkage studies in families with Type I diabetes mellitus. Diabetologia 43: 800-808

13. Rust S, Funke H, Assmann G (1993) Mutagenically separated PCR (MS-PCR): a highly specific one step procedure 
for easy mutation detection. Nucleic Acids Res 21: 3623-3629

14. Sunden S, Alward W, Nichols B et al. (1996) Fine mapping of the autosomal dominant juvenile open angle glaucoma (GLC1A) region and evaluation of candidate genes. Genome Res 6: 862-869

15. Spielman R, Ewens W (1996) The TDT and other familybased tests for linkage disequilibrium and association editorial. Am J Hum Genet 59: 983-989

16. Sham P, Curtis D (1995) An extended transmission/disequilibrium test (TDT) for multi- allele marker loci. Ann Hum Genet 59: 323-336
17. Devlin B, Risch N (1995) A comparison of linkage disequilibrium measures for fine-scale mapping. Genomics 29: 311-322

18. Holtz-Heppelmann CJ, Algeciras A, Badley A, Paya C (1998) Transcriptional regulation of the human FasL promoter-enhancer region. J Biol Chem 273: 4416-4423

19. Larsen Z, Kristiansen O, Mato E et al. (1999) IDDM 12 (CTLA4) on 2q33 and IDDM 13 on $2 \mathrm{q} 34$ in genetic susceptibility to type 1 diabetes (insulin-dependent). Autoimmunity $31: 35-42$ 